\title{
Power Parameter Design and Relevant Research of Snow Plough
}

\author{
Mu Cunyuan \\ Industrial Design Department \\ Shenyang Jianzhu University \\ Shenyang, Liaoning, China \\ e-mail: ysyz@sizu.edu.cn
}

\author{
Yao Wei \\ Industrial Design Department \\ Shenyang Jianzhu University \\ Shenyang, Liaoning, China \\ e-mail: 1047734497@qq.com
}

\begin{abstract}
The purpose of the paper is to design power parameters of snow plough and some relevant research of snow plough in order to improve transport efficiency of vehicles, improving winter driving conditions and avoiding accidents. The paper gives some common methods of snow removal and their advantages and disadvantages. By analyzing and calculating, the paper analyzes the engine power of rotary snow plough is composed of 3 parts of snow throwing power, surplus power and the power of snow plough travel. The paper calculates the snow throwing distance and the power of snow removing that difference with the difference of snow density, the speed of the snow plough and the rotate speed of the collector, and calculates the travel power of the snow plough. It also discusses the problems of blind area caused by guiding tube and solution. It can be the reference for relevant designers.
\end{abstract}

Keywords- power parameter; design; calculation; snow removing; blind area

\section{INTRODUCTION}

The most parts of northern China have three to five snowfall months every year, hundreds of thousands of kilometers roads there have the problem of snow removal. Snowing roads bring many difficulties to the traffic and people's lives. Sometimes, it even causes traffic disruption, affecting the normal development of the national economy. To be able to be quickly removed the road of snow, it is essential to achieve that the development of highway snow removing machinery mechanized snow removal operations. Mechanized snow removal operations are of great significant in improving transport efficiency of vehicles, improving winter driving conditions and avoiding accidents [1]. Each time snowing, the staff and workers of various units must go to the site to clean up the snows, this phenomenon not only do they waste time and energy as well as money, but also influence working process and traffic unsafe problems. In order to reduce the losses caused by this phenomenon, we have to design a special snow removing machinery to improve the situation above. In general, there are four methods to remove snow on the road.

\section{A. Manual cleaning}

Each station, workshop, intermediate station should have all kinds of emergency equipment such as brooms, shovels, wind snow blower and so on. When it snow, almost all the people, whether cadres, office staff, or off-duty workers, will go to the road to clean the snow.

\section{B. Snow removal by using chemical antifreeze}

When it is snowing, we can ensure the snow timely melt and does not freeze by making use of antifreeze on the road. Although this method can save man's power, it will cause environmental pollution. The antifreezes which are commonly used mainly are ethanol antifreezes, ethylene glycol antifreeze and glycerin type. Common antifreezing salt is sodium nitrite, which is also widely used in industrial building on the antifreeze. Its defect is toxic and corrosive, which can cause salt erosion to equipment and shorten the equipment's service life greatly.

\section{Snow removal by using electric heating products}

By using the principle that electricity eventually converts to thermal energy, we can achieve the result of melting snow and ice. On some important road section such cross roads or bridges and flyovers, geothermal heating device can used to ensure the road on snow. The problem of this method is it cost too much.

\section{Snow removal by using the device according to mechanical principle design}

Energy conservation and environmental protection has become the most important problem for countries around the world. Because of the shortcomings of power and energy consumption of heating snow removal system, people started to carry on the application of mechanical principles and to design all kinds of snow removal deicing device.

\section{RELEVANT RESEARCH OF SNOW PLOUGH}

The figure 1 is the two kinds of working directions and snow collecting device of the rotary snow plough. The figure 1 shows that it throw the snow into the roadside in the distance (the dash line arrow), and the snow are removed and go directly into a truck loaded

(the thin solid line arrow). The schematic diagram can be seen that from straight ahead of throwing snow plough which driving along the opposite direction, facing the throwing snow plough. 


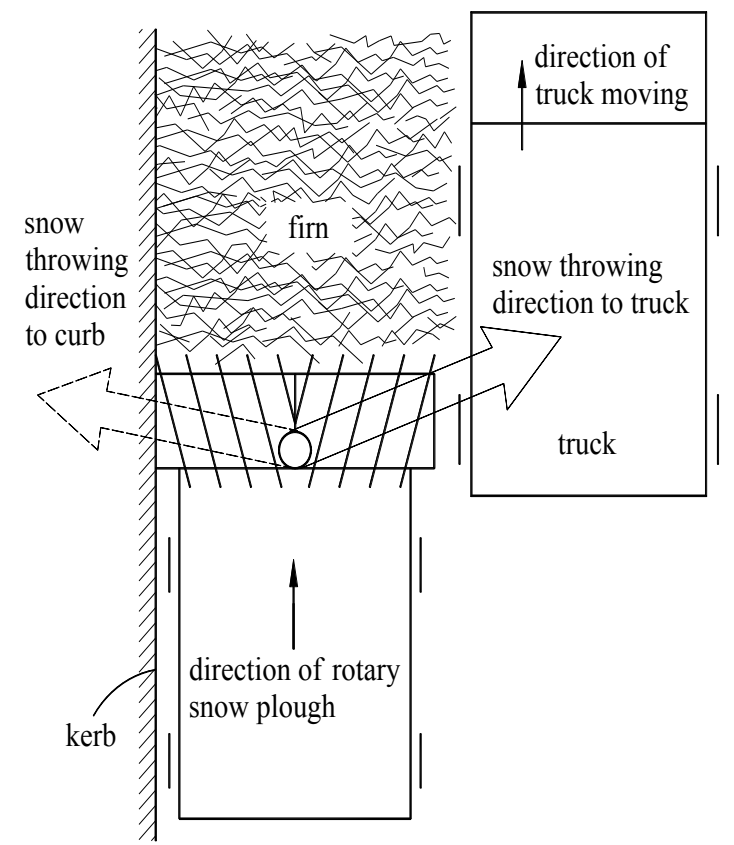

Figure 1 the direction of snow throwing

The figure 2 shows the around schematic diagram each have four heads diagram each have four heads spiral slice, that the spin in the opposite direction, and the pitch is $\mathrm{p}$. When they works, the schematic diagram

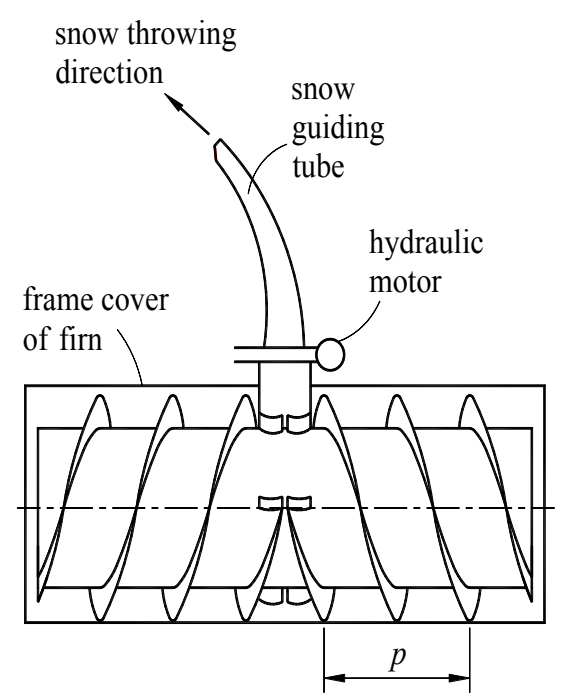

Figure 2 the composing of snow removal equipment

follows the synchronous rotation along the direction of the arrow on the graphic and the car forward at the same time [2]. Along the axis of the snow be squeezed by the spiral sheet from both sides to the middle. That by the radial blade with the role of the throwing snow relies on centrifugal force throws the snow out the guide groove. In order to adapt to different ways of working, the hydraulic motor driving can adjust the guide groove direction [3]. Because the guide grooves top is two meters high from the ground, and the throwing snow angle is $45^{\circ}$, it can cross the street roadside obstacles thrown the snow away directly, as shown in figure 1 . The snow can also be directly loaded into trucks, as shown in figure 1. The transmission form of the Rotary snow plough will be showed in the following. Snow throwing movement by the engine after the transfer case, the hydraulic pump and the oil motor, the drive shaft, the gearbox, transmit power to snow throwing device. In snow throwing device, the gearbox transmits power to axis in the snow by the bevel gear so that can put the spiral to rotate [4-5], the transmission line: Engine $\rightarrow$ Transfer case. After transfer case, the transmission line divided into two directions, one is "Transmission $\rightarrow$ Bevel gear $\rightarrow$ Axle $\rightarrow$ Helical segments", and the other one is "Variable oil pump $\rightarrow$ Hydraulic motor $\rightarrow$ Transmission $\rightarrow$ Walking device".

\section{POWER PARAMETER DESIGN}

\section{A. The power distribution of rotary snow plough}

The power distribution of rotary snow plough in figure 3 is as follows:

$$
N_{E}=N_{P}+N_{T}+N_{S}
$$

$N_{E}$ - engine power;

$N_{P}$ - power of snow throwing;

$N_{T}$ - power of snow plough travel;

$N_{S}$ - surplus power

As we can be seen from the above, when the $N_{T}$ is 0 , the engine power can be transmitted to all of the snow throwing device; when $N_{P}$ is 0 , the engine power can all become the running power. Therefore, when the snow removing have large amount, the speed should not too high; while the snow removing amount is little, you can improve the speed accordingly. Hence, rotary snow plough has higher transmission efficiency [6].

\section{B. The main indicators of peeling snow removal} vehicles:

- The shortest distance of throwing snow: $8 \mathrm{~m}$;

- Snow width: $2.6 \mathrm{~m}$

- Snow productivity: $1200 \mathrm{t} / \mathrm{h}$;

- $\quad$ Throwing snow tube speed : 209 515 t/min;

- Travel speed of throwing snow vehicle: 2-10 $\mathrm{km} / \mathrm{h}$.

\section{The estimates of Snow throwing distance}

When you ignore air resistance, it will affect snow throwing tube structure and other factors. Throwing snow $L$ in theory can drawn from the above mentioned [7-9].

The snow throwing distance be calculated by

$$
\begin{gathered}
L=\frac{v^{2}}{\mathrm{~g}} \sin 2 \alpha \\
L=\frac{4 \pi^{2} R^{2} n^{2}}{3400 \mathrm{~g}} \sin 2 \alpha
\end{gathered}
$$

If $R=0.495 \mathrm{~m}, \alpha=45^{\circ}, n=209 \sim 515 \mathrm{rpm}$, the distance of throwing snow will be $L=(11.7 \sim 71.2) \mathrm{m}$. 
$v$ - Throwing snow line speed, $\mathrm{m} / \mathrm{s}$;

$\mathrm{g}$ - Acceleration of gravity, $\mathrm{g}=9.8 \mathrm{~m} / \mathrm{s}^{2}$;

$R$ - The outer radius of the helical segments, $\mathrm{m}$;

$n$ - Throwing snow tube speed, $\mathrm{r} / \mathrm{min}$;

$a$ - Snow throw angle, degree. It is the angle between the snow away from the top of the guide slot when the direction of the snow with the ground.

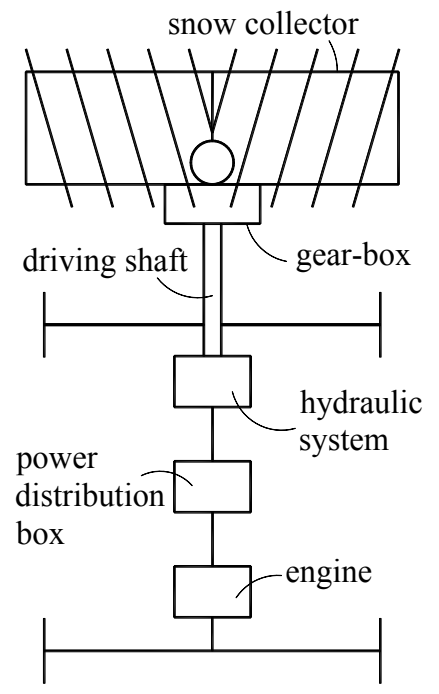

Figure 3 the power distribution of snow plough

\section{The power of snow removing}

The power of snow removing is difference with the difference of snow density, the speed of the snow plough and the rotate speed of the collector, according to reference [10-11], the power of snow removing is conform to the actually situation:

$$
\begin{aligned}
N_{P}= & 0.075\left[0.0133+0.042 \frac{\mu_{f}}{p}\left(d_{1}-\frac{100}{9} \times \frac{v}{n_{1}}\right)\right. \\
& \times \cos ^{2} \delta+0.0133 \mu_{f} \sin \delta \cos \delta \times K_{1} f Q(\mathrm{~kW})
\end{aligned}
$$

The meaning and the value of the symbols in the formula are as shown in table I. Substitute the values for the symbols, the formula will be:

$$
\begin{aligned}
N_{P}= & 0.075\left[0.0133+0.042 \frac{0.1}{1.667}(0.9\right. \\
& \left.-\frac{100}{9} \times \frac{4.104}{209}\right) \times 0.9629+0.0133 \times \\
& 0.1 \times 0.98126 \times 0.1927] \times 0.6 \times \\
& 37632 \times 1.1 \\
= & 29.023(\mathrm{~kW})
\end{aligned}
$$

\begin{tabular}{|c|c|c|c|}
\hline symbol & meaning & value & unit \\
\hline$v$ & speed of the snow plough & 4.401 & $\mathrm{~km} / \mathrm{h}$ \\
\hline$d_{1}$ & $\begin{array}{l}\text { the diameter of the spiral } \\
\text { rotary }\end{array}$ & 0.99 & $\mathrm{~m}$ \\
\hline$p$ & the pitch of the spiral & 1.667 & $\mathrm{~m}$ \\
\hline$\mu_{f}$ & $\begin{array}{l}\text { the dynamic friction of snow } \\
\text { and steel }\end{array}$ & 0.1 & \\
\hline$K_{1}$ & coefficient of spiral shape & 0.6 & \\
\hline$\rho$ & density of snow & 300 & $\mathrm{~km} / \mathrm{m}^{3}$ \\
\hline$f$ & $\begin{array}{l}\text { broken resistance force of } \\
\text { pressed snow } \\
f=24(\rho-140) L g\end{array}$ & 37632 & $\mathrm{~N} / \mathrm{m}^{3}$ \\
\hline$Q$ & $\begin{array}{l}\text { Productivity of snow } \\
\text { removing }\end{array}$ & 1.1 & $\mathrm{~m}^{3} / \mathrm{s}$ \\
\hline
\end{tabular}

TABLE I THE SYMBOLS MEANING AND THE VALUE OF THE FORMULA (1)
E. Travel power of the snow plough

According to reference [10-11], the power of travel power of the snow plough will be:

$$
\begin{aligned}
N_{T}= & \left\{\mu_{r} W \cos \theta+W \sin \theta+\left[10(v-12)^{2}\right.\right. \\
& \left.\left.+1700 \times \frac{\rho}{380} \times K\right] A\right\} \frac{v}{\left(367 \eta_{m} \eta_{n}\right)}(\mathrm{kW})
\end{aligned}
$$

The meaning and the value of the symbols in the formula are as shown in table II. Substitute the values for the symbols, the formula will be:

$$
\begin{aligned}
N_{T}= & \left\{0.0214 \times 4900+\left[10(4.104-12)^{2}+\right.\right. \\
& \left.\left.1700 \times \frac{300}{380} \times 0.6\right] 2\right\} \frac{4.104}{367 \times 0.9 \times 0.77} \\
= & 47.80(\mathrm{~kW})
\end{aligned}
$$

TABLE II THE SYMBOLS MEANING AND THE VALUE OF THE FORMULA (2)

\begin{tabular}{cccc}
\hline symbol & meaning & value & unit \\
\hline$W$ & $\begin{array}{c}\text { the total weight of the } \\
\text { snow plough }\end{array}$ & 4900 & $\mathrm{~kg}$ \\
$\mu_{r}$ & $\begin{array}{c}\text { coefficient of resistance } \\
\text { force }\end{array}$ & 0.0214 & \\
$\theta$ & $\begin{array}{c}\text { slope of the road } \\
\text { shape coefficient }\left(K=K_{1}\right)\end{array}$ & 0.6 & $\circ$ \\
$K$ & $\begin{array}{c}\text { section area of snow } \\
\text { removed }\end{array}$ & 2 & $\mathrm{~m}^{2}$ \\
& $\begin{array}{c}\text { efficiency of machinery } \\
\text { transmission }\end{array}$ & 0.9 & \\
$\eta_{m}$ & $\begin{array}{c}\text { efficiency of hydraulic } \\
\text { transmission }\end{array}$ & 0.77 & \\
$\eta_{n}$ & $\quad$ & & \\
\hline
\end{tabular}

\section{F. Rotary-type snow mechanics application}

Currently, snowy country in winter have two methods to clean snow, there are melting and mechanical methods. Melting method is to rely on thermal effects or spreading chemicals to make snow melt. However, this method has high cost and can cause the pollution of the environment, so its use is restricted. Mechanical method is a method by direct mechanical action on the ice while lifting snow hazards, including peeling type of snow removal vehicles in highway snow 
removal that has increasingly shown its superiority. The operating range is wider, normally used for the following applications:

- $\quad$ Remove new snow

New snow with low density, so the snow removal operations are the most economical in state of new snow, but it has large time-limits factors effort.

- Remove real snow

New snow is usually compacted before removed, it especially in heavy traffic urban area. This can use the methods to remove the snow through the type of wedge plow in combination with the rotary cutting; this method can make full use of their respective advantages and improve the work efficiency.

- Widening Snow

On the broad road or airport, square, etc. This snow removal operation is rather special. Using the method of spiral type snow removing is the most economical method, while throwing snow into the truck away.

- Removing snow of sidewalk

The sidewalks on both sides of the road, and the roads of the factory, it is not necessary and Uneconomical if there use the wedge plow. While, the small hand-handle snow plough with rotary cutting is more convenient and flexible.

\section{G. Blind area problem caused by guiding tube and solution}

Since the guiding tube is just located at the middle of the snow collector, this place is just in front of the driver, so it will cause the problem of blind area and has a strong impact on driving vision which shown in shadow area in figure 4.

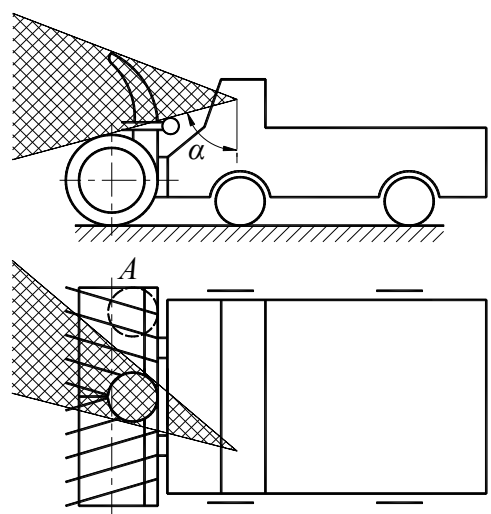

Figure 4 blind area caused by guiding tube

To move the guiding tube to the side of the collector such as the place A shown in figure 4 in order to open the visual field of the driver. The disadvantage of this method is that the hand of helix is in one direction (right or left) and make the snow plough subjected to side force, so this method is not for large snow plough.

Use the flat-head truck to decrease the angle $\alpha$ shown in figure 4 . The driving vision of flat-head truck is better than long head trucks especially removing snow with high speed and the flying snow fog cover the driver's window. Experiments show that flat-head truck is little influence by flying snow fog.

\section{CONCLUSION}

The snow plough with rotary cutting type in snowy countries has developed very quickly in recent decades, the mechanical character are also being perfected and it has gradually achieve serialization products. By analyzing and calculating, the distance of throwing snow can be 11.7 71.2 meters, this is enough to through snow to the side of general road. The power distribution of rotary snow plough is composed of power of snow throwing, power of snow plough travel and surplus power. The power of snow throwing is $29.023 \mathrm{~kW}$, and the power of snow plough travel is $47.80 \mathrm{~kW}$.

In order to avoid the blind area caused by guiding tube, the guiding tube can be moved to the side of the collector, or use the flat-head truck to decrease the blind area.

\section{REFERENCE}

[1] Ning Wenxiang. Schmidt Snow Plough Stand out in Global Market [J]. SPECIAL PURPOSE VEHICLE. 2009.10. 35-37

[2] Dong Dongshuang, Deng Hongchao, Ma Wenxing. Power allocation analysis of hydraulic system with single pump and multiple motors of multifunctional snow-plough [J]. Transactions of the Chinese Society of Agricultural Engineering. 2010, 26(7). pp140-146

[3] Si Guimao, Lei Yuan, Zhang Tiejiang. Design and Calculation of Hydraulic System of Snow Removal Vehicle [J]. Road Machinery \& Construction Mechanization. 2013.12. 94-97

[4] $\mathrm{Xu}$ Xiaofen et al. Design of New Snow Plough and De-icing Vehicle [J]. Special Purpose Vehicle, 2010.8. 44-46

[5] Liu Jiangnan, Liu Qiuping. Study of the Contradiction and Innovation of the Road Snowplow of Engineering Vehicles [J]. Journal of Hunan University (Natural Sciences). 2011.6(38). 33-37

[6] Yao Jiwei, Sun Kuan. Current situation and development trend of the road snow removing machinery [J]. Construction Machinery. 2013.6.68-73

[7] Zheng Dongli, Ke Xianzhi, Wang Chao, Li Peng, Yang Yanju. Calculation is based on the dynamic performance SX3317DR404 snow dump truck chassis modified cars [J]. Automobile Applied Technology. 2014.2.81-83

[8] Xia Jianman et al. A New Cast Snow Blower on Base of Fork Lift [J]. Special Purpose Vehicle. 2009,7. 48-49

[9] Robert L. Mott. Machine Elements in Mechanical Design [M] Prentice Hall; United States ed of 5th revised ed. March 2013. $0-816$

[10] David G. Ullman. The Mechanical Design Process [M].McGraw Hill Higher Education; 4th revised edition. March 2009. 0-448

[11] Cui Xianjiang. Snow Removing Machinery [M]. China communications press. Beijing, 1988.77-84 